\title{
Roberto Cardoso de Oliveira (1928-2006) Un amigo y colega del CIESAS
}

\author{
Virginia García Acosta
}

$\mathrm{R}$ oberto Cardoso de Oliveira, el inolvidable antropólogo brasileño, estuvo hasta el final de su vida cerca del Centro de Investigaciones y Estudios Superiores en Antropología Social (CIESAS). Unas semanas antes de su fallecimiento, aceptó gustoso y complacido la invitación que le hiciéramos para que su libro publicado por esta institución en 1979, Identidad y estructura social, fuera uno de los tres títulos con los que se iniciara la colección Clásicos y Contemporáneos de la Antropología. Se trata de una colección de publicaciones seleccionadas por ser consideradas fundamentales como apoyo a la docencia en antropología, producto de una colaboración tripartita entre las universidades Autónoma Metropolitana-Iztapalapa e Iberoamericana y el CIESAS que por esos meses estaba apenas iniciándose. El "mestre" Roberto, como solíamos llamarlo varios de quienes fuimos sus estudiantes, consintió de inmediato: primero por correo electrónico y después por teléfono. Al indicarle que la reedición de su libro acompañaría la de El hambre en Sudzal, de Guillermo Bonfil, el 3 de julio de 2006 Cardoso me escribía: "Querida Virginia: Só tenho a agradecer a lembrança de meu nome para iniciar essa colecção ao lado de nosso grande amigo Bonfil!’ Y añadió: "Dentro de algumas semanas deve sair meu novo livro

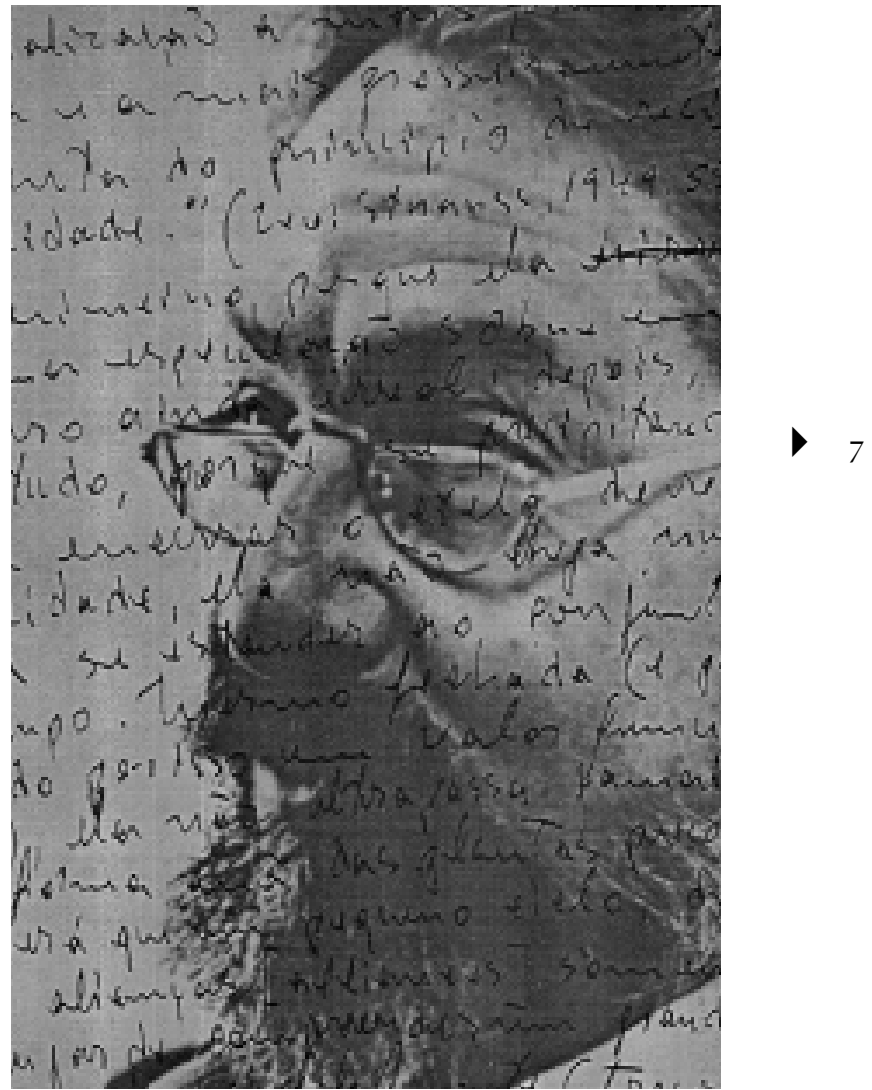

VIRGINIA GARCÍA ACOSTA: Centro de Investigaciones y Estudios Superiores en Antropología Social-Distrito Federal, México dirgral@ciesas.edu.mx 


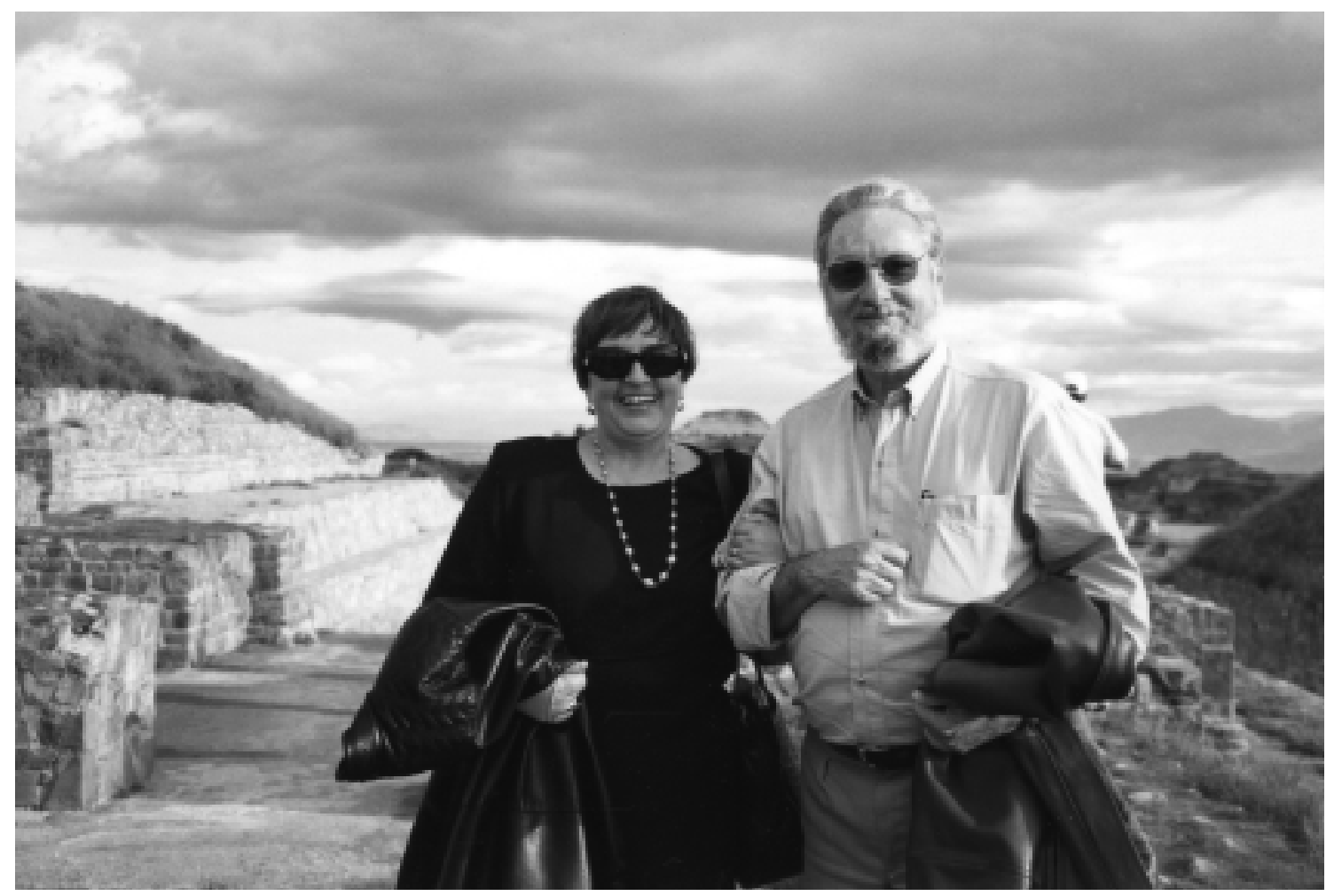

Gilda y Roberto Cardoso de Oliveira en México.

sobre o assunto, intitulado Caminhos da identidade: ensaios sobre etnicidade e multiculturalismo. Claro que tão logo eu receba exemplares estarei enviado para vocês". En esa ocasión, como siempre, se despidió por partida doble: "Beijos de Gilda e abraços saudosos do Roberto".

Si bien su relación con los antropólogos y la antropología mexicana era ya añeja pues, entre otros, participó en el memorable VI Congreso Indigenista Interamericano que se llevó a cabo en Pátzcuaro en 1968 y desde inicios de la década de 1970 invitó a estudiantes mexicanos a trabajar con él en la Universidad de Brasilia: Virginia Molina Ludy de abril a septiembre de 1973, y María Eugenia Vargas de julio a diciembre de 1975, ambas hoy investigadoras del CIESAS. Cardoso incluso participó en ese mismo año en el comité académico del doctorado de María Eugenia Vargas en el CISINAH (Centro de Investigaciones Superiores del Instituto Nacional de Antropología e Historia).
Su colaboración sistemática con esta institución se inició a fines de la década de 1970. Fue durante el periodo en el que Guillermo Bonfil fungió como director de esta institución, todavía con su apelativo original de CISINAH, que Cardoso fue invitado como profesor visitante al programa de doctorado. Estuvo con nosotros dictando cursos y conferencias entre agosto de 1979 y enero de 1980. En esa ocasión, entre septiembre y diciembre, dictó el "Seminario avanzado de estudios étnicos", en el cual participamos, además de los estudiantes del doctorado, los miembros del entonces vigente "Programa de estudios étnicos" y del recién concluido "Programa sobre minorías étnicas no indígenas", cuyos productos estaban en esos años siendo publicados.

Por entonces, Cardoso se encontraba vinculado a la Universidad de Brasilia, a la mitad de un periodo que alcanzaría 13 años (1972 a 1985), durante los cuales fue profesor titular en el Departamento de Antropología. Si 


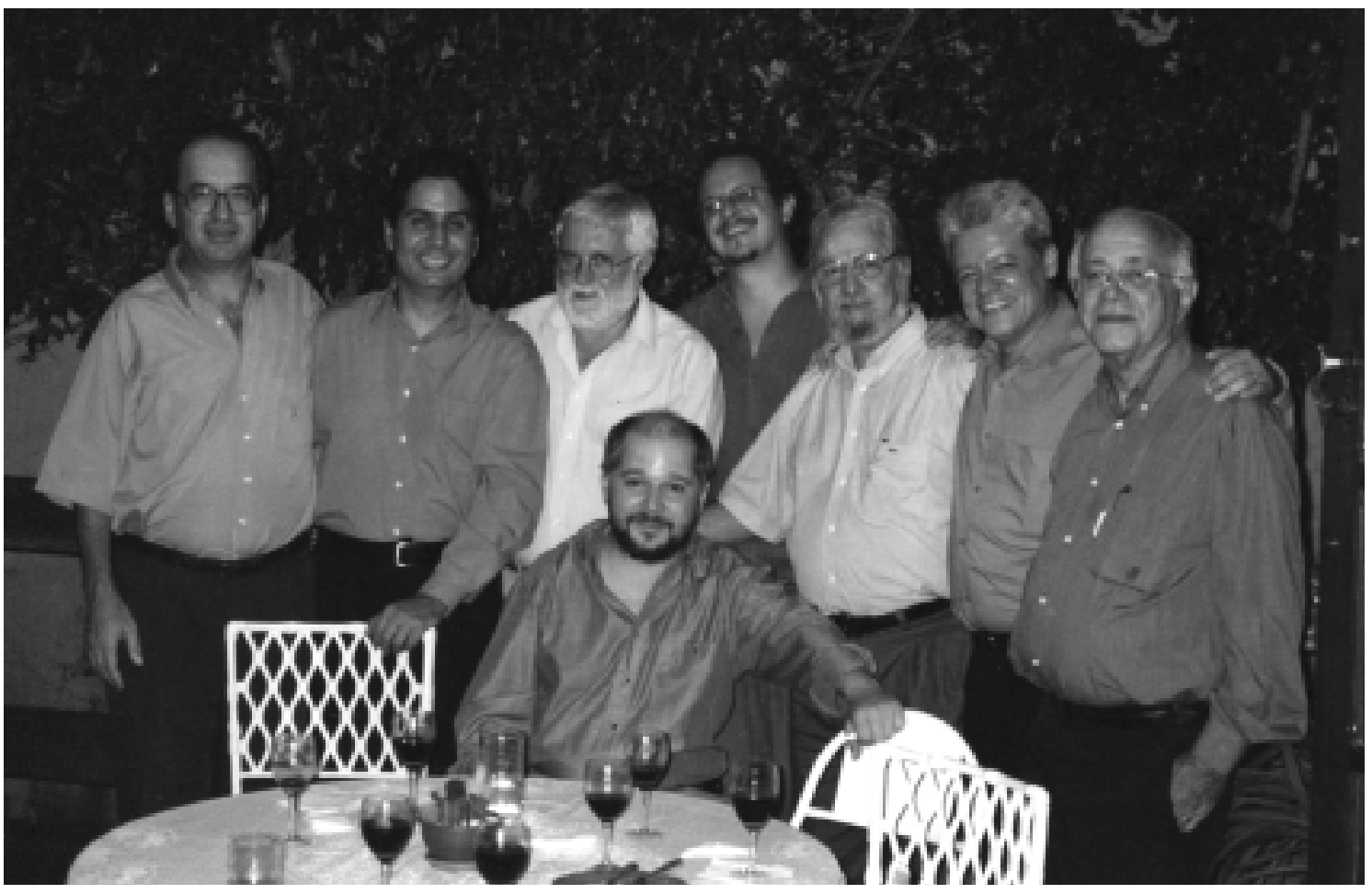

Roberto Cardoso de Oliveira, en su casa, en 2005, rodeado por los antropólogos Ruben Oliven, Gustavo Ribeiro, Alejandro Grimson, su hijo Luís Roberto y Roque Laraia, más algunos no identificados.

bien sus grados (bacharel y licenciado en filosofía — 1952 y 1953 - y doctor en ciencias/sociología I - 1966) los obtuvo todos en la Facultad de Filosofía, Ciencias y Letras de la Universidad de São Paulo, y que la Universidad Estatal de Campinas le otorgara el emeritazgo en 1997, la Universidad de Brasilia, a la que estuvo vinculado hasta el final de sus días, lo tuvo siempre entre sus profesores predilectos, muestra de lo cual fue el doctorado Honoris Causa que le otorgó en 2003. La Universidad Federal de Río de Janeiro se lo otorgó en 1989.

Fue a raíz de esa estancia de Cardoso en el CIESAS que se inició el intercambio de investigadores, y más tarde de estudiantes, entre esta institución y la Universidad de Brasilia primero y de Campinas más tarde. A mí me tocó la fortuna de cursar un semestre académico en la maestría de antropología social en la Universidad de Brasilia en 1980, cuando Brasilia estaba entrando a su mayoría de edad. Tomé cursos con el propio Cardoso y con otros profesores, como Lia Zanotta Machado. Más tarde, ya en la década de 1990 y asesorados por Roberto, obtuvieron su doctorado en ciencias sociales en Campinas Mariano Báez Landa y Patricia Ponce Jiménez, hoy investigadores del CIESAS en su sede Golfo.

El semestre académico que cursé en Brasilia fue, sin duda, inolvidable; dejó marcas indelebles tanto en lo profesional como en lo personal: Brasil, su antropología, su cultura, su sensibilidad, constituyen experiencias que no debe perderse quien tenga la oportunidad de vivirlas de manera directa. Y en medio de todo ello, el "mestre" Roberto.

Tratar a Roberto Cardoso de Oliveira en su medio permitía conocerlo de otra manera. Era todo un personaje, respetado y hasta reverenciado por sus colegas y, sobre todo, por sus estudiantes. Era un honor, en calidad de estudiante, ser invitado a su casa, en la que nos ofreció una cena de despedida al final de nuestra estancia en Brasilia. Esa hermosa casa en la zona del lago de la ciudad candan- 


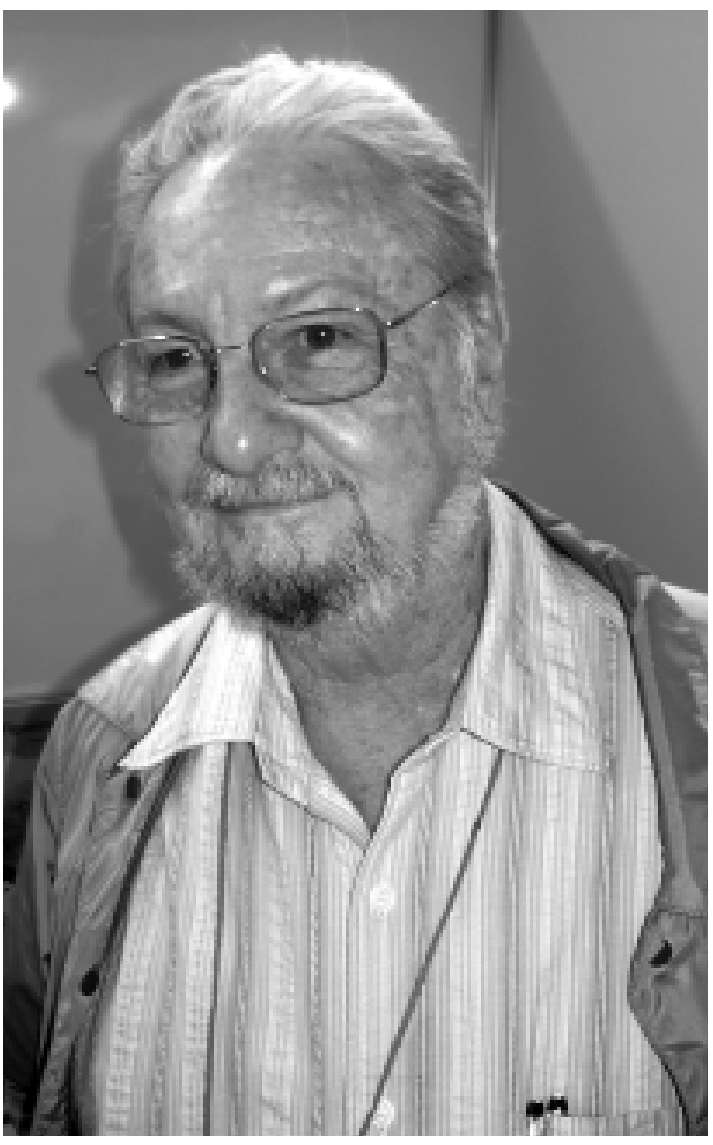

Roberto Cardoso de Oliveira.

ga, en cuyo jardín se habían reproducido sendas casas terêna y tükúna; en su estudio, flanqueando ambos lados de su escritorio, se encontraban las fotos de los que él mismo bautizó como "os pais da casa": Claude Lévy-Strauss y Marcel Mauss.

Como yo en esas épocas andaba todavía enfrascada en los estudios sobre grupos étnicos no indígenas, y poco antes había terminado una investigación sobre los españoles en México, Cardoso me animó a trabajar el caso de los portugueses en Brasil: dos grupos de inmigrantes que, habiendo sido originalmente los invasores-conquistadores en cada país, cuatro siglos y medio más tarde ocupaban nichos y respondían a estereotipos radicalmente distintos. Hice trabajo de campo en Río de Janeiro, hospedada en casa de su hijo Luís Roberto que, por enton-

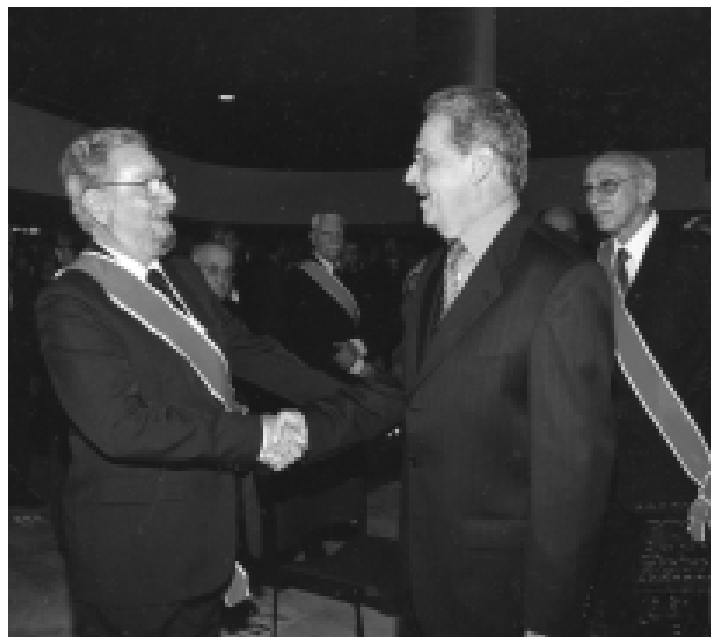

Con el presidente de Brasil, a finales de la década de 1990.

ces, estaba recién casado y tenía una pequeña y bella hija. Roberto me revisó no sólo el proyecto, sino también discutió conmigo las fichas resultantes del trabajo de campo que darían como producto el trabajo que hube de entregarle del curso que tomé con él.

No regresó a una estancia larga con nosotros, pero siempre se mantuvo en contacto estrecho. Con regularidad nos enviaba sus publicaciones, que se encuentran en la Biblioteca Ángel Palerm, ubicada en la sede del CIESAS en el Distrito Federal. Entre ellas, una de las más originales es la que reúne sus diarios de campo, escritos en la década de 1950, sobre las investigaciones que llevó a cabo entre los indígenas del Amazonas, los terêna y los tükúna: Os diários e suas margens, publicado por la Universidad de Brasilia en 2002 y dedicado a su compañera de siempre, Gilda, y a sus cuatro hijos: Luís Roberto, Rodolfo, Maria Fernanda y Lúcia.

Hasta el final, Roberto fue miembro del comité editorial de esta revista, Desacatos, invitación que le hiciéramos en 2005 y que, como siempre, aceptó gustoso y honrado.

Recordaremos siempre su seriedad y camaradería, su formalismo y su método, su carisma y sus enseñanzas.

México-Distrito Federal, enero de 2007 